\title{
Rhetorical Questions, Relevance and Scales
}

\author{
Javier Gutiérrez Rexach \\ The Ohio State University
}

\begin{abstract}
Rhetorical questions, and other varieties of pragmatically conditioned questions, present a challenge for a purely truth-conditional theory of the interpretation of interrogatives. In this paper, it is argued that relevance-theoretic principles account for the conditions of use of rhetorical questions. Concretely, it is proposed that a pragmatic principle, the "Bottom of Scale Principle", critically interacts with the Principle of Relevance and derives the dynamic meaning of the rhetorical use of a question. The Bottom of Scale Principle is also associated with the particular entailment and monotonicity properties of interrogatives, which explain the ability of rhetorical questions to license negative polarity items.
\end{abstract}

\section{Introduction}

In recent years, the analysis of the linguistic forms of interpersonal communication or dialogues has become one of the subjects of most intensive research in semantics and pragmatics, from the linguistic, philosophic and computational point of view --see Asher (1997) for a summary. Three theories emerged in the eighties that had the analysis of discourse and dialogue, in its semantic and pragmatic aspects, as their main focus: Situation Semantics (Barwise and Perry, 1983); Discourse Representation Theory (Kamp, 1981); and Relevance Theory (Sperber and Wilson, 1986).

One of the main purposes of relevance theoretic accounts of meaning is to abandon the traditional view of pragmatic content as given by the equation: Pragmatics $=$ meaning truth conditional content. The architecture of language cognition put forth by Relevance 
Theory defends a central contribution of pragmatics to the explicatures (Carston, 1988) of linguistic expressions that feed truth-conditional interpretation.

In this general setting, the analysis of speaker/hearer interactions through question/answer conversational exchanges offers an ideal ground for the study of the division of labor between semantics and pragmatics and the impact of relevance in discourse. In this paper, an analysis of rhetorical questions is presented in which special attention is paid to the idiosyncratic properties of the licensing of negative polarity items in these constructions. These properties will be considered central for a proper understanding of the semantics and pragmatics of rhetorical questions. Furthermore, it will be argued that a complete picture of the meaning of these constructions can only be offered if scalar aspects that affect relevance are taken into account.

The paper is structured as follows: in the second section, rhetorical questions are distinguished from information questions and the essentials of a relevance-theoretic treatment are presented; in sections three and four, the basic cross-linguistic facts of negative polarity licensing in rhetorical questions are presented, several approaches to this phenomenon are discussed, and a semantic solution is defended; finally, in section four, the initial account of the pragmatics of questions is supplemented with a principle derived from scalarity -the Bottom of Scale Principle-- whose interaction with the Principle of Relevance explains the conditions of use of rhetorical questions.

\section{Information questions and rhetorical questions}

Consider the following sentence:

\section{(1) Who cares about Bosnia?}

The interrogative sentence above may be understood as a request for information, what in the following will be called an information question. When a speaker $s$ utters (1), $s$ is asking the addressee to provide some information that $s$ estimates relevant (Sperber and Wilson, 1986). In answering (1), the addressee fills a gap in $s$ ' knowledge or information state. As Bach and Harnish (1979) put it: "Questions are special cases of requests, special in that what is requested is that the speaker provide the hearer with certain information".

Interrogative statements involve a bi-directional interaction between a speaker and a hearer/addressee. The consideration of this interaction is central for the study of the semantics and pragmatics of questions but is not captured in the most prominent approaches to the semantics of questions within the model-theoretic paradigm. For Hamblin (1973) and Karttunen (1977), a question denotes a set of propositions. The difference between the conceptions of these two authors is that for Hamblin an interrogative statement denotes the set of its possible answers whereas for Karttunen it denotes the set of its true answers. ${ }^{1}$ The translation of (1) into a formula of the language of intensional logic that implements Karttunen's conception would be as follows: ${ }^{2}$ 
(2) $\lambda \mathrm{p}\left[\exists \mathrm{x}\left[\mathrm{p}={ }^{\wedge}\right.\right.$ Care about Bosnia'(x) $\left.] \wedge \operatorname{True}(\mathrm{p})\right]$

In a situation in which Bill Clinton and Helmut Kohl care about Bosnia, the above formula would denote the following set:

\section{(3) \{'Care about Bosnia'(Helmut Kohl'), 'Care about Bosnia'(Bill Clinton')\}}

since these two propositions would be the only true propositions satisfying the condition in (2). As becomes clear, Karttunen's theory is agent independent, in the sense that it does not capture the idea of information flow from speaker to addressee and viceversa. Nothing is said about the different possibilities that arise in an information exchange with respect to the utterance of (2) or of any of the answers in (3). In addition, the set in (3) represents the individual propositions ${ }^{3}$ that jointly constitute the complete true answer to (2), but are not related to the linguistic form of possible renditions of complete true answers to (2). Wilson and Sperber (1988), following Bolinger (1978), raise another objection for the standard model-theoretic account. Within Karttunen's conception, the three questions in (4) would have the same meaning, since they would denote the same set of propositions, namely the set in (5). Nevertheless it seems clear that the sentences below cannot be uttered felicitously in the same contexts.

(4) a. Did you see Susan?

b. Didn't you see Susan?

c. Did you or did you not see Susan?

(5) a. $\left\{{ }^{\wedge} \operatorname{See}(\operatorname{Susan})(\right.$ you $), \wedge \neg \operatorname{See}(\operatorname{Susan})($ you $\left.)\right\}$

Consequently, the truth-conditional approach seems to fail to capture not only the conditions of use of the above sentences but also their dynamic content or role in a conversation exchange, in other words, how uttering each of the sentences in (4) may have different repercussions in the information state of the participants in a conversation.

The class of questions under discussion in this paper, rhetorical questions, represent a more direct challenge for a purely semantic account of the meaning of questions. Sentence (2) above may express a rhetorical question when associated with a particular intonation pattem. ${ }^{4}$ In that case, the sentence cannot be interpreted as a request for information on the part of the addressee but rather as an assertion. Sadock $(1971 ; 1974)$ claims that rhetorical questions have the illocutionary force of a strong assertion. More concretely, positive rhetorical questions such as the examples in (6) have the illocutionary force of a negative assertion, as the equivalent declarative statements in (7) illustrate. On the other hand, negative rhetorical questions, such as the examples in (8), have the illocutionary force of a positive assertion and are equivalent to the declarative sentences in (9).

(6) a. Who could be interested in Astronomy these days? 
b. Who has ever been to Katmandu?

c. Are you going to pass any exam?

(7) a. Nobody is interested in Astronomy these days

b. Nobody has ever been to Katmandu

c. You are not going to pass any exam

(8) a. Who couldn't be interested in Astronomy these days?

b. Who hasn't ever been to New York?

c. Aren't you going to pass any course you try?

(9) a. Everybody is interested in Astronomy these days

b. Everybody has been to New York some time

c. You are going to pass any course you try

Sadock $(1971 ; 1974)$ proposes a series of tests that set rhetorical questions apart from information questions. These tests apply equally to yes/no questions and $w h$-questions. ${ }^{5}$ First, the introductory expression after all can occur with rhetorical questions but cannot occur with information questions. For instance, $(10)$ can only be interpreted as a rhetorical question.

(10) After all, are you coming to the party?

Second, rhetorical questions can be followed by a clause headed by the item yet. This is not possible in the case of information questions.

(11) Did I receive help from anybody? Yet, I managed to complete my tasks on time

The parenthetical expression by any chance may be used in rhetorical question, but not in an information question. The question in (12) tends to be not interpreted as a request for information.

(12) Is John coming, by any chance?

Finally, if a rhetorical question is used as a parenthetical it can adopt the form of a nonrestrictive relative clause, as illustrated in (13a). On the other hand, information questions must adopt the form of a conjunct when used as parentheticals, as the contrast between (13b) and (13c) shows.

(13) a. Symbolic logic, which who cares about anyway, is awfully tough.

b. Symbolic logic, and by the way who invented it?, isn't my cup of Postum.

c. *Symbolic logic, which by the way who invented, isn't my cup of Postum. 
Rhetorical questions, as well as echo questions, quiz questions, exam questions, etc.(Bell, 1975) have proven to be elusive for strictly model-theoretic treatments and have become the cornerstone of arguments in favor of the superiority of a relevance-theoretic analysis of questions (Wilson and Sperber, 1988; Blakemore, 1994). Wilson and Sperber (1988) argue that their distinction between descriptive and interpretive uses (Sperber and Wilson, 1986) is essential for the understanding of questions that do not constitute requests for information from an illocutionary point of view. Descriptive uses are associated with descriptive representations. A representation is descriptive or truth-conditional if and only if what is represented is "a relation between thoughts or utterances and states of affairs" (Wilson and Sperber, 1988: 87). On the other hand, a representation is interpretive if and only if what is represented is "a relation between thoughts or utterances and other thoughts or utterances that they resemble" (op. cit.:87). When a thought or utterance is used to represent another thought or utterance, it is called an interpretive use.

Wilson and Sperber claim that interrogative utterances are always interpretively used and the corresponding representation is what the speaker considers as the relevant answer. An interrogative utterance achieves relevance by representing its answer as desirable. The semantic variability of questions, in other words, the explanation of why they are not always requests for information, comes from the intrinsic indeterminacy of the notion of relevance, defined in terms of cognitive effect. In different contexts ${ }^{6}$ this indeterminacy may be pragmatically resolved as a function of who the speaker thinks would regard the represented thought as desirable. In the case of information questions, optimal relevance is achieved in the direction of the speaker, in other words the answer is relevant to him in the sense that it updates his information state in the desired dimension. In the case of rhetorical questions, "the semantic indeterminacy is resolved in the hearer's favor" (Wilson and Sperber, 1988: 98). The speaker indicates that he regards the answer as relevant to the hearer.

The above characterization of rhetorical questions supplements the semantic perspective with the consideration of a pragmatic dimension. In rhetorical questions, the speaker already knows the answer to the question but calls the hearer's attention to a thought or proposition that is being expressed by the question. More specifically, the relevant thought is already in the knowledge base or information state of the speaker and the rhetorical question makes this fact apparent to the hearer. Consider a situation in which $\mathrm{A}$ is telling $\mathrm{B}$ that he has a tight schedule and he will not be able to finish the assigned task during the next month. B knows that $A$ has reservations for a one week vacation in the Bahamas in fifteen days. Then, B utters the following question:

(14) Aren't you going to the Bahamas?

The interrogative sentence (14) represents the following proposition:

(15) You are going to the Bahamas 
Proposition (15) is not relevant to the speaker $\mathrm{B}$, because this proposition is part of his cognitive information state and just recovering it amounts to little cognitive impact (it is not informationally relevant). (15) is relevant for A because he is not aware that the speaker knows his vacation plans, so the excuses for not completing the assigned task on time do not sound truthful.

Han (1997) argues that rhetorical questions denote their negative answers. This characterization is not sufficient because it does not allow us to distinguish rhetorical questions from negative confirmation questions and tag questions. Negative confirmation questions are very similar in their form to rhetorical questions. The interrogative sentence (16) can be uttered as a negative confirmation question. In that case, the speaker is assuming that Fred is coming to dinner but wants confirmation of this fact from the addressee, who presumably has more information in this respect.

(16) Isn't Fred coming to dinner?

The confirmation question in (16) would denote, within Han's (1997) account, its negative answer, namely the proposition Fred is coming to dinner. This would make it indistinguishable from its use as a rhetorical question. (16) would be felicitous as a rhetorical question in a situation in which the speaker knows that Fred is coming to dinner but wants to make that fact relevant to the hearer. On the other hand, (16) is felicitous as a confirmatory question, or as the confirmatory use of a question, in a situation in which the speaker is not sure of whether Fred is coming to dinner and wants to confirm his initial assumption that he will. The distinction between a rhetorical and a confirmatory use of (16) is not truth-conditional, but rather represents a difference in the direction of relevance. In confirmation questions, the represented thought or proposition is relevant to the speaker. He wants to confirm whether an assumption in his knowledge base is true or not. In contrast, as we have seen above, rhetorical questions represent propositions as desirable for the hearer. The represented thought or proposition is held as a presupposition in the information state of the speaker. This is why the expressed thought is not relevant to him.

\section{Rhetorical questions and negative polarity licensing}

Rhetorical questions impose strict conditions on the logical form or explicature (Carston, 1988) of their responses. First, the polarity of the answer is the opposite of the polarity of the corresponding question, as illustrated in (6-9) above. This constraint does not seem to follow from the pragmatic conditions discussed in the previous section. What I will argue in the following is that the presence of a covert decreasing operator in the logical form of the interrogative statement, corresponding to the interrogative illocutionary operator, is what triggers the behavior of rhetorical questions with respect to polarity. To show this point, a related issue has to be analyzed in more detail: the licensing of negative polarity 
items (NPIs) and the proposals that have been made in the literature to account for their occurrence in rhetorical questions.

From a descriptive point of view, NPIs are words (any, ever, etc) and phrases of diverse categories ( $a$ single thing, lift a finger, etc.) that occur or are licensed in a very specific and restricted set of environments (Ladusaw, 1979): within the scope of sentential or VP negation, within the scope of decreasing quantifiers, as complements of adversative predicates, in the protasis of conditionals, in before-clauses and in matrix and embedded interrogative sentences.

Not all NPIs have the same distribution. There are (at least) two different classes that I will call, following Zwarts (1990), weak NPIs and strong NPIs. Expressions such as any, anybody, anything, yet, etc. are weak NPIs. They can occur in the scope of the negation operator (17a) or in the argument of any decreasing generalized quantifier $(17 \mathrm{~b}, \mathrm{c})$.

(17) a. He has not been to Moscow ever.

b. Nobody has ever been to Moscow.

c. Fewer than five students have ever been to Moscow.

Expressions such as give a damn, at all, in weeks, until, a bit, lift a finger and budge an inch impose a stronger requirement on their licensing. They occur in the scope of negation and in the argument or c-command domain of generalized quantifier expressions like nobody $(18 \mathrm{a}, \mathrm{b})$, but they do not occur in the c-command domain of generalized quantifier expressions like few $(A)$ or not more than three $(A)$, where $A$ is any common noun $(18 \mathrm{c}, \mathrm{d})$.

(18) a. He did not arrive until five.

b. Nobody ate anything at all.

c. *Few students arrived in weeks.

d. ${ }^{*}$ Not more than three policemen lifted a finger to help us.

As an initial generalization, it seems evident that weak and strong NPIs are licensed in interrogative sentences. An additional characterizing property of this class of constructions is that the presence of an NPI triggers the rhetorical interpretation of the question. The occurrence of a strong NPI in a question obligatorily triggers a rhetorical reading, a fact already noticed by Borkin (1971) and Lawler (1971):

(19) a. Who bats an eye when the boss comes around?

Represented thought: Nobody bats an eye when the boss comes around.

b. Who has seen Harriet in years?

Represented thought: Nobody has seen Harriet in years.

c. Who lifted a finger to help when I needed it?

Represented thought: Nobody lifted a finger to help when I needed it.

d. Does John read anything at all?

Represented thought: John did not read anything at all. 
e. Did a single person read Barriers?

Represented thought: Not a single person read Barriers.

The rhetorical reading is optional in yes/no questions with weak NPIs. In normal conditions, when a speaker is trying to disambiguate the two readings (rhetorical and non-rhetorical), he places focal stress on the NPI when the rhetorical reading is the one intended (20). There is also a typical intonational contour associated with the rhetorical use that completely disambiguates the interpretation of the sentence. In $w h$-questions with weak NPIs we observe the same ambiguity (21) and the intended reading is also prosodically resolved.

(20) a. Does John read anything?

b. Has anybody ever read Barriers?

c. Has Mary ever kissed anybody on the first date?

(21) a. Who has ever been to Moscow? (ambiguous)

b. Who did Mary ever kiss on the first date? (rhetorical reading preferred)

c. Who has ever kissed a girl on the first date? (ambiguous)

The situation is not uniform cross-linguistically. In Spanish, the presence of an NPI (22) or a negative quantifier (23) obligatorily triggers the rhetorical reading (see Bosque, 1980).

(22) a. ¿Quién da un duro por los bosnios? (only rhetorical)

who gives a coin for the bosnians

'Who gives a damn about the bosnians?'

b. ¿Quién de vosotros ha podido pegar ojo? (only rhetorical)

who of you has could close eye

'Who was able to sleep at all?'

c. ¿Cuándo daremos abasto? (only rhetorical)

when give-us enough

'When would we be able to handle it?'

d. ¿Quién ha levantado un dedo para salvarnos? (only rhetorical)

who has lifted a finger to save-us

'Who has lifted a finger to save us?'

(23) a. ¿Ha dicho alguien nada? (only rhetorical)

has said somebody nothing

'Has anybody said anything?' (rhetorical)

b. ¿Qué ha hecho nadie en este departamento recientemente?

what has done nobody in this department recently

'What has anybody ever done in this department?' (rhetorical) 
In Spanish there is no source for ambiguity. The informative counterparts of the interrogative sentences in (23) would be as in (24), where an existential quantifier is substituted for the negative quantifier.

(24) a. ¿Ha dicho alguien algo? has said somebody something 'Has anybody said anything?' (information question)

b. ¿Qué ha publicado alguien en este departamento recientemente? what has published somebody in this department recently 'What have people in this department published recently?'

The "avoid ambiguity in the syntax" strategy of Spanish, contrasts with the essentially prosodic strategy of English where, as mentioned above, focal stress or a specific intonational contour disambiguate questions with weak NPIs. We have two additional facts that confirm the hypothesis proposed for Spanish. First, the presence of the adverb acaso 'by-any-chance' activates the rhetorical reading of the question when there are no NPIs in the sentence, as predicted by the third of Sadock's tests. This adverb can only occur in yes/no questions, as the contrast in (25) shows. Second, whereas the NP algún libro 'some book' is a positive polarity item (26a), the NP libro alguno 'book some' is an NPI. Hence, only the latter triggers a rhetorical reading (26b).

(25) a. ¿Ha dicho alguien algo acaso? (rhetorical) has said somebody something by-any-chance 'Has anybody said anything?'

b. ${ }^{*}$ ¿Qué ha publicado alguien en este departamento acaso? what has published somebody in this department by-any-chance

(26) a. ¿Ha visto Pedro algún extraterrestre? has seen Pedro some extraterrestrial 'Has Pedro seen any extraterrestrial?' (non-rhetorical)

b. ¿Ha visto Pedro extraterrestre alguno? has seen Pedro extraterrestrial some 'Has Pedro seen any extraterrestrial?' (rhetorical)

In Catalan and Italian, NPIs are licensed in yes/no questions (Zanuttini, 1991; Progovac, 1994). This is also the case of Hindi, according to Lahiri (1995). ${ }^{7}$ In other languages like Chinese, $w h$-words can also act as negative polarity items. Huang (1982: 108) presents the following inventory: shei 'who/anybody', sheme 'what/anything', na 'which/any', heshi 'when/ anytime', nali 'where/any place', zeme 'how/any way', weisheme 'why/any reason'. The sentences in (27), according to Zhang (1991), are ambiguous between the interpretation (I) and (ii). Serbo-Croatian displays a similar behavior, as the example in (28), taken from 
Progovac (1994), illustrates.

(27) a. Shei zhidao?

who know

(I) 'Who knows?' or (ii) 'Who knows?' (rhetorical) = 'I don't know'

b. Shei da ren le?

who hit person ASP

(I) 'Who hit someone?' or (ii) 'Who hit anyone?' (rhetorical) = 'I didn't hit anyone'

(28) Da li je Milan (I-)šta doneo?

that $\mathrm{Q}$ has Milan any-what brought

'Has Milan brought anything?'

\section{Syntactic, semantic and pragmatic accounts}

The range of cross-linguistic variation that we have presented suggests that there are two different issues that should receive an independent answer: (I) why are NPIs licensed in interrogative sentences? and (ii) where does the rhetorical reading come from? Issue (ii) has been partly addressed in the previous section and will also be the main topic of section five below. Issue (I), which logically precedes issue (ii), is the main topic of this section.

Ladusaw (1979) proposes a general explanation for the licensing of negative polarity items, following Fauconnier's (1975) theory of scalarity: NPIs are licensing when they occur in the scope of a decreasing operator. We say that an operator is decreasing if and only if the following holds:

(29) For all A, B of type $\alpha$ such that $A \leq B$, where $\leq$ represents an ordering relation on expressions of type $\alpha, O p(B) \leq O p(A)$

Negation is a decreasing operator, and this explains why NPIs are licensed within its scope. Surprisingly, Ladusaw's explanation of the occurrence of polarity sensitive items in questions is not directly based on decreasingness but rather in a pragmatic principle relating form and meaning:

(30) S[peaker] should pose the question $q$ only when he believes it to be possible for $\mathrm{H}$ [earer] to express its denotation set without major revision of the form of the question.

Thus, when a speaker asks a question like (31a), he is expecting that the hearer is going to express the answer in a form that does not change the form of the question. Obviously, since 
the interrogative sentence contains an NPI, the only possible declarative response will be one containing a negation ( $31 \mathrm{~b})$.

(31) a. Did John ever lift a finger to help?

b. No, he didn't ever lift a finger to help.

Ladusaw's theory predicts that the only possible reading of sentence (31a) is the rhetorical one. Krifka (1991) observes that Ladusaw's account leaves unexplained why NPIs can also occur in neutral or information questions, as illustrated in $(20,21)$ above. The principle in (30) also poses conditions on the expressiveness of rhetorical questions which are stricter than necessary. Sentence (32a) can be uttered by a speaker $s$ as a rhetorical question. According to principle (30), he would expect (32b) as the answer to the rhetorical question, because this is the declarative sentence whose form would constitute the least revision of the form of the question. But the speaker's expectations are the opposite, since the relevant proposition expressed by the question is that he did not come.

\section{(32) a. Did he come?}

b. Yes, he came.

Progovac's (1994) theory attempts to give an explanation of NPI licensing based primarily on the syntactic constraints of binding theory within a Government and Binding model of syntax. For the cases in which NPIs occur in non-overtly negative environments, such as conditionals and questions, she proposes that there is a null operator that binds the NPI. NPIs licensed by an element other than clausemate negation have to raise at LF. Horn and Lee (1995) observe that her analysis wrongly predicts that strong NPIs like budge an inch or lift a finger are licensed only by clausemate negation since they are not Qpsa nd cannot raise at LF. Therefore, Progovac's analysis does not explain why idiomatic strong NPIs occur in questions. Second, with respect to the rhetorical reading, she states that "in order to derive rhetorical force in wh-questions it is enough to assume that wh-AGR and Op in Comp are incompatible, both requiring a separate interpretation in the Comp position ... The only remaining option is to suppress wh-AGR in Comp, resulting in the loss of the $w h$-force ... Since only negated NPIs are tolerated in the Spec of CP, the operator in Comp must set its switch to the negative value, and due to Spec/Head AGR, the wh-word gets interpreted as a negated NPI." (Progovac, 1994: 98-99)

There are several problems for this line of explanation. First, $w h$-words in questions with NPIs display full agreement (overtly realized and semantically relevant). Second, the rhetorical interpretation of a question is sometimes optional, namely when weak NPIs occur in it as in (20) and (21). Progovac's theory wrongly predicts that the presence of an NPI automatically triggers the "loss of the $w h$-force". Finally, no distinctions are made among NPIs.

Krifka's (1991) theory posits a combination of semantic and pragmatic factors for the licensing of NPIs in different constructions. Specifically he defends that "the pragmatic setting of asking questions" has to be examined more closely if rhetorical readings are to be accounted 
for. On the semantic side, he presents a lattice-theoretical approach to NPIs. He introduces the concept of a polarity lattice defined as a triple $\mathbf{L}_{\mathrm{A}}=\left\langle\mathbf{a}^{\prime}, \mathrm{L}_{\mathrm{A}},{s_{\mathrm{a}}}^{\prime}\right.$, where $\mathbf{a}^{\prime}$ is the NPI representation, $L_{\mathrm{A}}$ is the lattice sort and the following conditions hold: (a) if $\mathbf{a}^{\prime}$ is of type $\sigma, \mathbf{L}_{\mathrm{A}}$ is of type $\left\langle\sigma, t>\right.$, (b) $\leq_{a}$ is a preorder relation on $L_{A},(c) a^{\prime} \in L_{A}$, and $L_{A}$ contains at least one more element, and (d) a' is the unique $\mathrm{Y}$ such that for every $\mathrm{X} \in \mathrm{L}_{\mathrm{A}}, \mathrm{Y} \leq_{\mathrm{a}} \mathrm{X}$. For example, the polarity lattice of the NPI $a$ drop of wine is $<$ a.drof.of.wine', $\mathrm{L}_{\text {adrop.ofwine, }} \leq_{\text {adrop.ofwinc }}>$, where for all properties $X$, if $X \in \mathrm{L}_{\text {adropo: } \text { wine }}$ then $X$ is the property of being a quantity of wine of a certain size and a.drop.of.wine' is the least element of the lattice (i.e. $\forall x\left[\right.$ a.drop.of.wine $(x) \rightarrow$ wine $^{\prime}(x) \wedge$ $\mathrm{x}$ is smaller than some quantity $\varepsilon]$ ). The process of question formation consists in attaching the illocutionary operator $E R O$ to the sentence radical. If $p^{\prime}$ is a proposition, $i$ a world, $s$ the speaker, and $h$ the hearer, then $E R O\left(s, h, i, p^{\prime}\right)$ says that $s$ asks $h$ whether $\boldsymbol{p}^{\prime}$ is true at the world $i$. In the case of rhetorical questions, Krifka claims that the speaker wants to show that he is sure to get a negative answer, so he follows the rule:

(33) If $E R O\left(s, h, i, A^{\prime}\right)$ and $\boldsymbol{a}^{\prime}$ is an NPI or PPI representation with lattice sort $\mathrm{L}_{\mathrm{A}}$, then for any $\mathrm{X} \in \mathrm{L}_{\mathrm{A}}$ with $\mathrm{X} \neq \boldsymbol{a}^{\prime}, s$ has reasons for $-E R O(s, h, i, X)$.

Consider the following interrogative sentence:

(34) Did you ever drink a drop of wine?

According to the rule, if a speaker $s$ asks question (34), then for any property $X$ in the polarity lattice $\mathrm{L}_{\text {admp of wmos }}, s$ has reasons for not asking whether a proposition containing $\mathrm{X}$ is true at $i$. The speaker asks a question only about the least element in the lattice, namely a.drop.of.wine'. From the point of view of the discussion of the pragmatics of rhetorical questions in section two, it is not clear whether the above rule captures the essence of what is a rhetorical question. The speaker is not even asking whether the proposition $p$ containing the least element in the relevant polarity lattice is true. He already knows what the answer is and he is asking it for reasons different than knowing whether $p$ is true in $I$. The question is uttered not as a request for information, but with other communicative purpose: to make the hearer aware of the relevance of $p$. In that respect, it seems reasonable to claim that in uttering a rhetorical question, for all $\mathrm{X}$ $\in \mathrm{L}_{\Lambda}$ the speaker $s$ has reasons for $\neg E R O(s, h, i, X)$. But even this modification would not yield a correct analysis. Rhetorical questions must be treated as questions from the illocutionary point of view, although they are obviously not requests for information. Krifka does not deal with the issue of what is the specific property of questions that allows the licensing of NPIs either. Finally, none of the rules he proposes predict the licensing of NPIs and rhetorical interpretations in constituent questions.

Here, I will argue, following Gutierrez-Rexach (1996), that the semantic property that explains the occurrence of NPIs in questions is decreasingness, along the lines of Ladusaw's (1979) proposal for negative contexts in general. No additional assumptions are needed. The question operator? that transforms a declarative statement $\phi$ into a question ? $\phi$ is decreasing and questions are decreasing contexts. In order to determine the monotonicity properties of the 
interrogative operator, first it has to be determined what kind of entailment relation arises in the interrogative domain. In this point I will follow Groenendijk and Stokhof's (1989) notion of entailment in the interrogative domain. They define the (propositional) entailment relation between interrogatives as follows:

(35) An interrogative $\phi$ entails an interrogative $\psi$ iff, whenever a proposition gives a complete and true answer to $\phi$, it gives such an answer to $\psi$.

Consider now the following examples:

(36) a. Which guests smoked?

b. Which guests smoked cigars?

There is a natural information-based relation between (36a) and (36b) above. In Groenendijk and Stokhof's terms, if proposition gives a complete true answer to (36a) it also gives a complete true answer to (36b). For instance, in a situation in which John and Fred smoked cigars and Bill smoked cigarettes, proposition (37a), expressed by sentence (37b), gives a complete true answer to (36a) and it also contains a complete true answer to (36b).

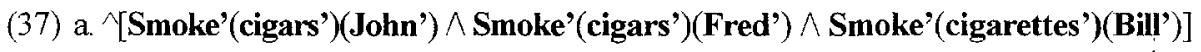
b. John and Fred smoked cigars and Bill smoked cigarettes

The presence of the interrogative operator makes a question decreasing. If a proposition $p$ entails a proposition $q$, then ? $q$ entails ? $p$. The proposition expressed by (38a) entails the proposition expressed by (38b). Then, it follows that a question representing (38b) will entail a question representing (38a). This is indeed the case, since (36a), the question whose corresponding answer would be (38b), entails question (36b), whose corresponding answer is (38a), as explained before.

(38) a. John and Bill smoke cigars

b. John and Bill smoke

The generalization that we arrive at is the following: attaching the question formation operator ? to a proposition $p$, transforms it into a question ? $p$. The proposition then becomes a decreasing environment and, as a straightforward corollary of Ladusaw's generalization, NPIs are licensed. ${ }^{8}$

\section{Scalarity and relevance}

Once the licensing of NPIs in questions in general has been accounted for, the problem now becomes to explain what pragmatic strategy is served by the systematic use of NPIs, specially strong NPIs, in rhetorical questions. It is important to realize that the previously offered 
explanation of the general mechanisms of NPI licensing, or any of the alternatives discussed, does not deal with this part of the meaning of rhetorical questions, related to their conditions of use. As pointed out above, only Krifka (1991) realizes that a complete account of the meaning of rhetorical questions requires a consideration of their pragmatics. a relevance-theoretic account does not suffer from the problems of an strictly illocutionary treatment, such as Krifka's, but needs additional developments to incorporate the effects associated to scalarity, something not mentioned by either Sperber and Wilson (1986) or Wilson and Sperber (1998).

According to Hom (1969) and Fauconnier (1975), pragmatic scales are orderings of lexical items associated to certain pragmatic effects, typically triggered by the elements at the top or at the bottom of the scale. As observed by Krifka (1991), NPIs can be considered members of contextually determined scales. For instance, the NPI lift a finger is a member of pragmatic scale having as its members VP denotations, more concretely actions. Those actions are ordered with respect to a contextually determined criterion. Crucially, NPIs obey the following constraint:

(39) Bottom of Scale Principle: strong NPIs always denote elements at the bottom of the contextually associated scale. Weak NPIs may also denote bottom of scale elements. ${ }^{9}$

In the sentence below, the presence of the NPI lift a finger brings in the entailment that John did not perform even the minimal action necessary to help Bill. The relevant ordering of the scale is determined by a criterion of effort or willingness --how much effort or willingness is required by a certain action. Obviously, the action of lifting a finger is at the bottom of that scale, so the desired entailment is brought about straightforwardly.

(40) John didn't lift a finger to help Bill

Consider now the question in (41). From the Bottom of Scale Principle, it follows that the presence of the NPI lift a finger in (41) triggers an associated context $\mathrm{C}$ formed by an ordered set of VP denotations in which lifi a finger is the bottom element. The intended ordering criterion is the same: actions are ordered with respect to the criterion of willingness/effort and the action of lifting a finger represent the least effort or involves the least willingness on the part of the agent.

(41) Did John lifi a finger to save us?

The thought represented by the rhetorical use of the question above is the following:

(42) John did not lift a finger to save us.

Furthermore, it is not possible to utter (41) as a non-rhetorical or information question. Why is this so? Because the presence of the NPI is obligatorily associated with the contextually ordered scale and, from principle (39), the only thought that the hearer can infer, according to the Principle of Relevance, is that the action performed by John was at the bottom of a scale formed 
by a set of actions (VP denotations). Under normal conditions, the hearer will infer that John did little or nothing to help the individuals mentioned in (41). Supplementing the relevance-theoretic explanation of the rhetorical use of questions with the standard principles communicatively related to pragmatic scales is, thus, necessary to explain why questions with strong NPIs, those that are obligatorily associated to the bottom of a scale, obligatorily trigger the rhetorical interpretation of a question. The desired interpretation arises as a consequence of the interaction between the Principle of Relevance and the Bottom of Scale Principle.

Summarizing, when a speaker utters a question and uses an NPI as part of that question, he is maximizing the cognitive impact of the question and he is easing the construal of that question as relevant to the hearer, ie. as a rhetorical question.

\section{Notes}

1. See Græenendijk and Stokhof (1996) for an complete and incisive evaluation of the various approaches to the semantics of interrogatives.

2. Formula (2) denotes the set of true propositions $p$ of the form 'Care about Bosnia'( $x$ ), where $x$ is an individual variable.

3. With this term I refer to propositions about individuals in a models, ie. propositions of the form ' $\mathbf{P}^{\prime}\left(\alpha^{\prime}\right)$ where $\mathbf{P}$ ' is a predicate constant and $\alpha^{\prime}$ is an individual constant (a proper name) or a variable.

4. See Escandell (1996) for a relevance-theoretic study of the pragmatics of intonation in questions.

5. Sadock proposes these tests to distinguish rhetorical yes/no questions from information seeking yes/no questions. Nevertheless, as the examples proposed here show, the test also apply to $w h$-questions.

6. The context of a proposition $p$ is a set of propositions $\mathrm{C}$. The contextual implications of $\mathrm{p}$ are those entailments of the union of $\mathrm{C}$ and $p$ (Sperber and Wilson, 1986).

7. Although Lahiri (p.c.) admits that NPIs are also licensed in constituent questions, obligatorily triggering the rhetorical reading.

8. The study of the monotonicity properties of wh-questions requires a more careful consideration of the monotonicity properties of interrogative quantifiers, as done in GutierrezRexach (1997).

9. The exceptionality of weak NPIs can be explained as a by-product of their widening behavior (Kadmon and Landman, 1993).

\section{Works cited}

Asher, Nicholas. "Discourse." Encyclopedia of Philosophy. London: Routledge (forthcoming), 1997.

Bach, Kent and Robert Harnish. Linguistic Communication and Speech Acts. Cambridge: MIT Press, 1979.

Barwise, John and John Perry. Situation Semantics. Cambridge: MIT Press, 1983.

Bell, M. "Questioning." Philosophical Quarterly 25 (1975): 193-212. 
Bolinger, Dwight. "Yes-No Questions Are Not Alternative Questions." Questions. Ed. H. Hiz. Dordrecht: Reidel, 1978. 87-105.

Borkin, Anne. "Polarity Items In Questions." Papers from the 7th Regional Meeting of the

Chicago Linguistics Society (1971): 53-62.

Blakemore, Diane. "Echo Questions: a Pragmatic Account." Lingua 94 (1994): 197-211.

Bosque, Ignacio. Sobre la Negación. Madrid: Cátedra, 1980.

Carston, Robyn. "Implicature, Explicature and Logical Form." Mental Representations. The

Interface Between Language and Reality. Ed. Ruth Kempson. Cambridge: Cambridge University Press, 1988. 155-182.

Escandell, Maria Victoria. "Intonation and Procedural Encoding in Interrogatives." Perspectives on Spanish Linguistics, Vol.1. Ed. Javier Gutiérrez and Luis Silva, Los Angeles: UCLA, 1996. 35-54.

Fauconnier, Gilles. "Polarity And The Scale Principle." Papers from the 11th Regional Meeting of the Chicago Linguistics Society (1975): 188-199.

Groenendijk, Jeroen and Martin Stokhof. "Type-Shifting Rules And The Semantics Of Interrogatives." Properties, Types and Meaning, Vol 2: Semantic Issues. Ed. Gennaro Chierchia. Dordrecht: Kluwer Academic Publishers, 1989.

Groenendijk, Jeroen and Martin Stockhof. "Questions." Handbook of Logic \& Language. Ed. Johan van Benthem and Alice ter Meulen. Amsterdam: North Holland, 1997. 1055-1124.

Gutiérrez-Rexach, Javier . "The Semantic Basis Of NPI Licensing In Questions. MIT Working Papers In Linguistics (Proceedings SCIL 8) 31 (1997).

Hamblin, Charles. "Questions in Montague English." Foundations of Language 10: 41-53.

Han, Chung-Hye. "Deriving The Interpretation Of Rhetorical Questions. Proceedings WCCFL 16, 1997.

Horn, Larry. On The Semantic Properties Of Logical Operators. Ph.D. dissertation. UCLA, 1969. Horn, Larry . and Lee, Y. "Progovac On Polarity." Journal of Linguistics 31(1995): 401-424.

Huang, James. Logical Relations In Chinese And The Theory Of Grammar. Ph.D. dissertation. MTT, 1982.

Kadmon, Nirit and Fred Landman. "Any." Linguistics and Philosophy 16 (1993): 353-422.

Kamp, Hans. "a Theory Of Truth And Semantic Representation." Truth, Interpretation And Information. Ed. Jeroen Groenendijk. Dordrecht: Foris, 1981. 277-321.

Karttunen, Lauri. “The Syntax And Semantics Of Questions." Linguistics and Philosophy 1 (1977): 3-44.

Krifka, Manfred. "Some Remarks On Polarity Items." Semantic Universals and Universal Semantics. Ed. Dietmar Zaefferer. Dordrecht: Foris.

Ladusaw, William. Polarity Sensitivity As Inherent Scope Relations. New York: Garland, 1979.

Lahiri, Utpal. "Negative Polarity in Hindi."Proceedings of SALT V. Ithaca: DMML, Comell University. 1995. 168-185.

Lawler, John. "Any Questions." Papers from the 7th Regional Meeting of the Chicago Linguistic Society (1971): 163-173.

Progovac, Liliana. Negative and Positive Polarity. Cambridge: Cambridge University Press, 1994.

Sadock, Jerrold. "Queclaratives." Papers from the 7th Regional Meeting of the Chicago Linguistic Society (1971): 223-232.

, Towards a Linguistic theory of Speech Acts. New York: Academic Press, 1974.

Sperber, Daniel and Deirdre Wilson. Relevance. Oxford: Basil Blackwell, 1986. 
Wilson, Deirdre and Daniel Sperber. "Mood And The Analysis Of Non-Declarative Sentences." Human Agency. Ed. J. Dancy et al. California: Stanford University Press, 1988, 77-101. Zanuttini, Raffaella. Syntactic Properties of Sentential Negation. Ph. D. thesis, University of Pennsylvania, 1991.

Zhang, Jie. "Question And Negation in Chinese." Papers from the 27th Regional Meeting of the Chicago Linguistic Society. Part Two: The Parasession on Negation (1991): 345-358.

Zwarts, Frans. "The Syntax And Semantics Of Negative Polarity.", ms., University of Groningen, 1990. 